\title{
Organic Geochemistry
}

\section{Field ionization mass spectrometric study of high molecular weight hydrocarbons in a crude oil and a solid bitumen}

\author{
José C. del Río ${ }^{\mathrm{a}, *}, \mathrm{R}$. Paul Philp ${ }^{\mathrm{b}}$ \\ anstituto de Recursos Naturales y Agrobiologia de Sevilla, CSIC, P.O. Box 1052, 41080 Seville, Spain \\ ${ }^{\mathrm{b}}$ School of Geology and Geophysics, University of Oklahoma, Norman, OK 73019, USA \\ Received 9 November 1998; accepted 1 February 1999 \\ (Returned to author for revision 22 December 1998)
}

\begin{abstract}
The occurrence of high molecular weight hydrocarbons in a selected solid bitumen (ozocerite) and a waxy yellow crude oil from the Uinta Basin (Utah) have been studied by field ionization-mass spectrometry (FIMS). The FIMS spectra consisted predominantly of molecular ions ranging up to near mass 2000 , and correspond to several series of hydrocarbons ranging up to $\mathrm{C}_{110}$. The use of FIMS permits the range of hydrocarbons identified in geological materials to be extended far beyond that identified by the usual chromatographic techniques. Moreover, from the FIMS spectra it was possible to extract the molecular ions corresponding to series of hydrocarbons with different degree of unsaturation or ring closures (different $Z$-numbers). The ozocerite solid bitumen consisted mainly of series of branched alkanes $\left(\mathrm{C}_{n} \mathrm{H}_{2 n+2}\right)$ and cyclic alkanes $\left(\mathrm{C}_{n} \mathrm{H}_{2 n}\right.$ and $\left.\mathrm{C}_{n} \mathrm{H}_{2 n-2}\right)$ up to $\mathrm{C}_{110}$ with a predominance of monocyclic alkanes in the high molecular weight region (above $\mathrm{C}_{40}$ ). The waxy yellow crude oil, on the other hand, contained only acyclic compounds, mainly $n$-alkanes, ranging up to $\mathrm{C}_{100}$. (C) 1999 Elsevier Science Ltd. All rights reserved.
\end{abstract}

Keywords: Field ionization mass spectrometry; High molecular weight hydrocarbons; Ozocerite; Solid bitumens; Uinta Basin oil; High temperature gas chromatography

\section{Introduction}

Organic geochemistry has been concerned mainly with the characterization of compounds present in the geosphere in the carbon number range up to $\mathrm{C}_{40}$. The occurrence of high molecular weight hydrocarbons $\left(>\mathrm{C}_{40}\right)$ in geological materials has received little attention until relatively recently for two main reasons. The first is the lack of appropriate techniques, since tra-

\footnotetext{
* Corresponding author. Tel.: +34-5-462-4711; fax: +34-5462-4002.

E-mail address: delrio@irnase.csic.es (J.C. del Río)
}

ditional gas chromatographic methods are limited to species with sufficient volatility. The second, particularly in the case of oils, is that the high molecular weight hydrocarbons (HMWHC) often are not present, or in very low concentrations in the oils collected at the well head. Rather, these compounds precipitate due to their low solubility and mobility at surface temperatures and pressures (del Río and Philp, 1992a; Aquino Neto et al., 1994; Philp, 1994; Philp et al., 1995).

The HMWHC are generally dominated by $n$ alkanes, although several authors have found that for carbon numbers over $\mathrm{C}_{40}$, iso- and/or monocyclic alkanes, rather than $n$-alkanes, can dominate the high 
temperature gas chromatography (HTGC) profiles of many crude oils and some solid bitumens and source rocks (del Río et al., 1992; Carlson et al., 1993; Mueller and Philp, 1998). Moreover, the distribution pattern of HMWHC in the carbon number range of $\mathrm{C}_{40}$ to $\mathrm{C}_{50}$ appeared to be useful in differentiating depositional environments of crude oils and source rocks (Carlson et al., 1993).

Different mass spectrometric techniques have been coupled with HTGC in order to gain more information on the structure and origin of these HMWHC. Gallegos et al. (1991) using HTGC-EIMS (electron impact mass spectrometry) and HTGC-FIMS (field ionization mass spectrometry) also identified series of isoalkanes and cycloalkanes with carbon numbers ranging up to $\mathrm{C}_{60}$ in crude oils, while de Grande et al. (1993) identified a series of tricyclic terpane homologs up to $\mathrm{C}_{54}$ in sediments and petroleums. In a recent study, Carlson et al. (1997) coupled HTGC-IRMS (isotope ratio mass spectrometry) and showed a similarity in carbon isotopic signatures of lower $n$-alkanes and the alkanes $>\mathrm{C}_{40}$, suggesting that both groups are formed either biologically or diagenetically from the same ancient carbon pool.

HTGC has some limitations in the analysis of high molecular weight components of oils and bitumens. The high temperatures (typically above $400^{\circ} \mathrm{C}$ ) required for HTGC raise the possibility of pyrolysis of some oil components, particularly the polar, heteroatom-containing compounds. Therefore, direct insertion of the HMWHCs in the mass spectrometer can be used as an alternative approach to avoid these problems. In this context, del Río et al. (1992) used direct insertion probe, (DIP)-EIMS, to identify a series of long chain alkylcyclohexanes and branched alkanes ranging up to $\mathrm{C}_{80}$ in a fraction of the ozocerite bitumen enriched in high molecular weight hydrocarbons. Boduszynski (1987, 1988) also identified numerous homologous series of compounds extending to over $\mathrm{C}_{100}$ in concentrates of heavy petroleums by using FIMS. However, the nature and origin of most of the high molecular weight hydrocarbons occurring in geological materials is still unclear and more studies are necessary.

In this paper we investigate the occurrence of high molecular weight hydrocarbons in selected solid bitumens and crude oils by direct insertion probe (DIP)field ionization mass spectrometry (FIMS). In the FIMS, the molecular ions formed in the ion source are separated by a magnetic field and hence the technique permits extension of the range of hydrocarbons that can be determined. The FIMS also permits the identification of molecular weights (and thus ring numbers) of high molecular weight hydrocarbons that exhibit no molecular ions in MS studies employing other ionization methods. This is an excellent method for analyz- ing complex mixtures since it yields practically fragment-free molecular ion spectra. This technique is therefore ideally suited for the characterization of crude oils and solid bitumens since the molecular weight distribution can be directly determined and the contribution from all the components evaluated.

\section{Experimental}

\subsection{Samples}

A solid bitumen, ozocerite, and a waxy yellow crude oil from the Bluebell Field, both from the Uinta Basin (Utah), were selected for this study. The samples have already been described in previous papers (del Río et al., 1992; Philp et al., 1995). The high molecular weight hydrocarbons were concentrated from the yellow crude oil by the addition of hot tetrahydrofuran followed by cooling overnight at $0^{\circ} \mathrm{C}$. The high molecular weight hydrocarbons which precipitated were subsequently removed by filtration.

\subsection{High temperature gas chromatography (HTGC)}

High temperature gas chromatography analyses were performed using a Carlo Erba gas chromatograph equipped with a short $6 \mathrm{~m}$ aluminum-clad capillary column coated with the HT-5 liquid film. The conditions were: split/splitless injector and flame ionization detector at $400^{\circ} \mathrm{C}$ and the column was heated from 60 to $440^{\circ} \mathrm{C}$ at a rate of $8^{\circ} \mathrm{C} / \mathrm{min}$ with $25 \mathrm{~min}$ final hold time. The samples were dissolved in warm $p$-xylene before injection.

\subsection{Field ionization-mass spectrometry (FIMS)}

The FIMS spectra were recorded in a VG AutoSpecQ mass spectrometer at VG Analytical (Manchester, UK). The samples were introduced through a retractable all glass heated inlet system (AGHIS), heated to between 300 and $350^{\circ} \mathrm{C}$. The ions were accelerated to $5 \mathrm{kV}$ operating in the positive-ion mode. Data were acquired at $5 \mathrm{~s} /$ decade from mass 100 to 2000, with a nominal mass resolution of FIMS of 1000 .

\section{Results and discussion}

The FI mass spectrum of the ozocerite solid bitumen is shown in Fig. 1. The FI mass spectrum consists of molecular ions ranging up to near mass 2000 which corresponds to series of hydrocarbons ranging up to $\mathrm{C}_{110}$. The ion peaks detected corresponded to the following $Z$ series: $\mathrm{C}_{n} \mathrm{H}_{2 n+2}$, acyclic alkanes; $\mathrm{C}_{n} \mathrm{H}_{2 n}$, 


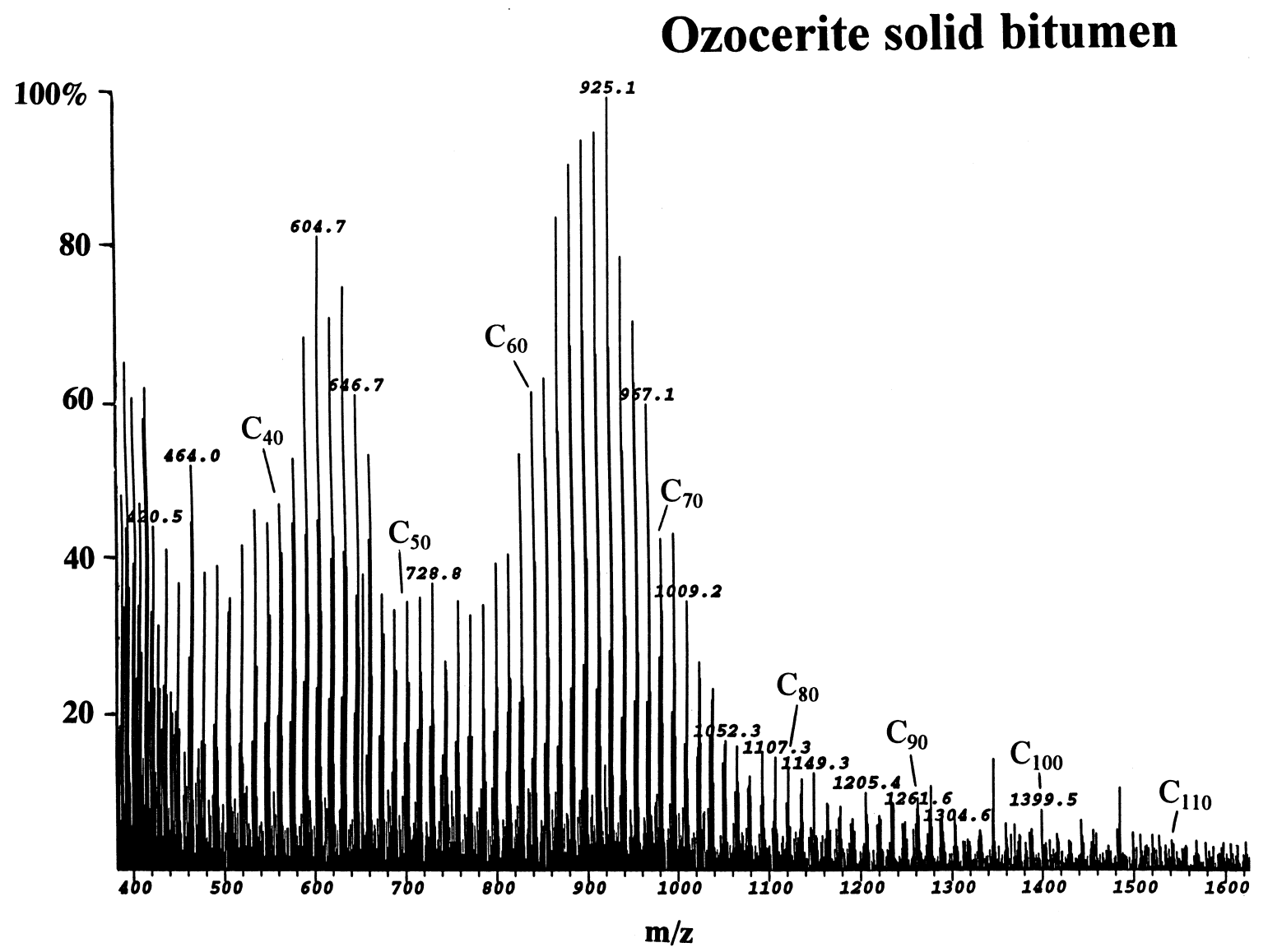

Fig. 1. FIMS of the total saturate fraction of the ozocerite solid bitumen.

monocyclic alkanes and $\mathrm{C}_{n} \mathrm{H}_{2 n-2}$, dicyclic alkanes. The molar mass peaks belonging to each $Z$ series are 14 amu $\left(\mathrm{CH}_{2}\right)$ apart. Each molar mass peak may be represented by a large number of isomers.

Several overlapping bell-shaped distributions with maxima centered at $\mathrm{C}_{43}$ and $\mathrm{C}_{66}$ were observed in the high molecular weight region (above $\mathrm{C}_{40}$ ) in the FIMS profile. The data are consistent with the analysis of the ozocerite solid bitumen by HTGC (Fig. 2) which showed a series of alkanes ranging up to $\mathrm{C}_{80}$, with two maxima in the high molecular weight region centered around $\mathrm{C}_{43}$ and $\mathrm{C}_{63}$. Some carbon predominance was observed in the $\mathrm{C}_{50}-\mathrm{C}_{70}$ region in the HTGC trace, in contrast to the FIMS profile. The differences in the distribution maxima and relative intensities observed in the FIMS and the HTGC are most likely due to peak broadening caused by coelution of several compounds in HTGC peaks, mainly alkanes having different $Z$ number, which are resolved in the FIMS. However, different discriminatory effects in the FIMS and HTGC sample introduction and/or differences in the ionization efficiencies of the acyclic and monocyclic components, cannot be ruled out to explain these differences.

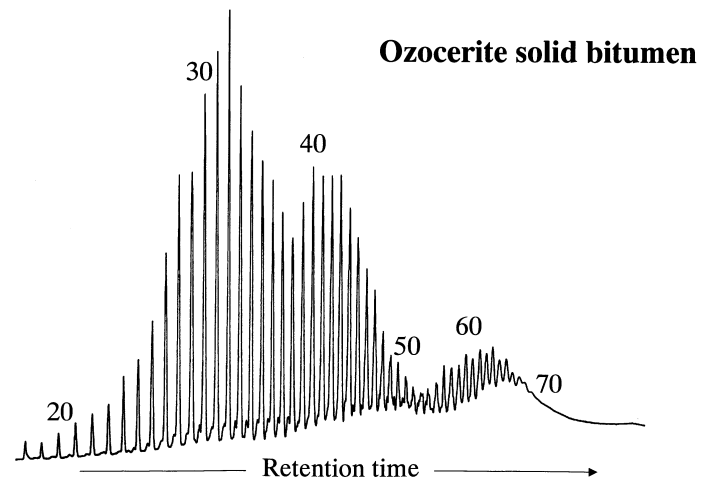

Fig. 2. Capillary HTGC (6 m) analysis of the ozocerite solid bitumen. 

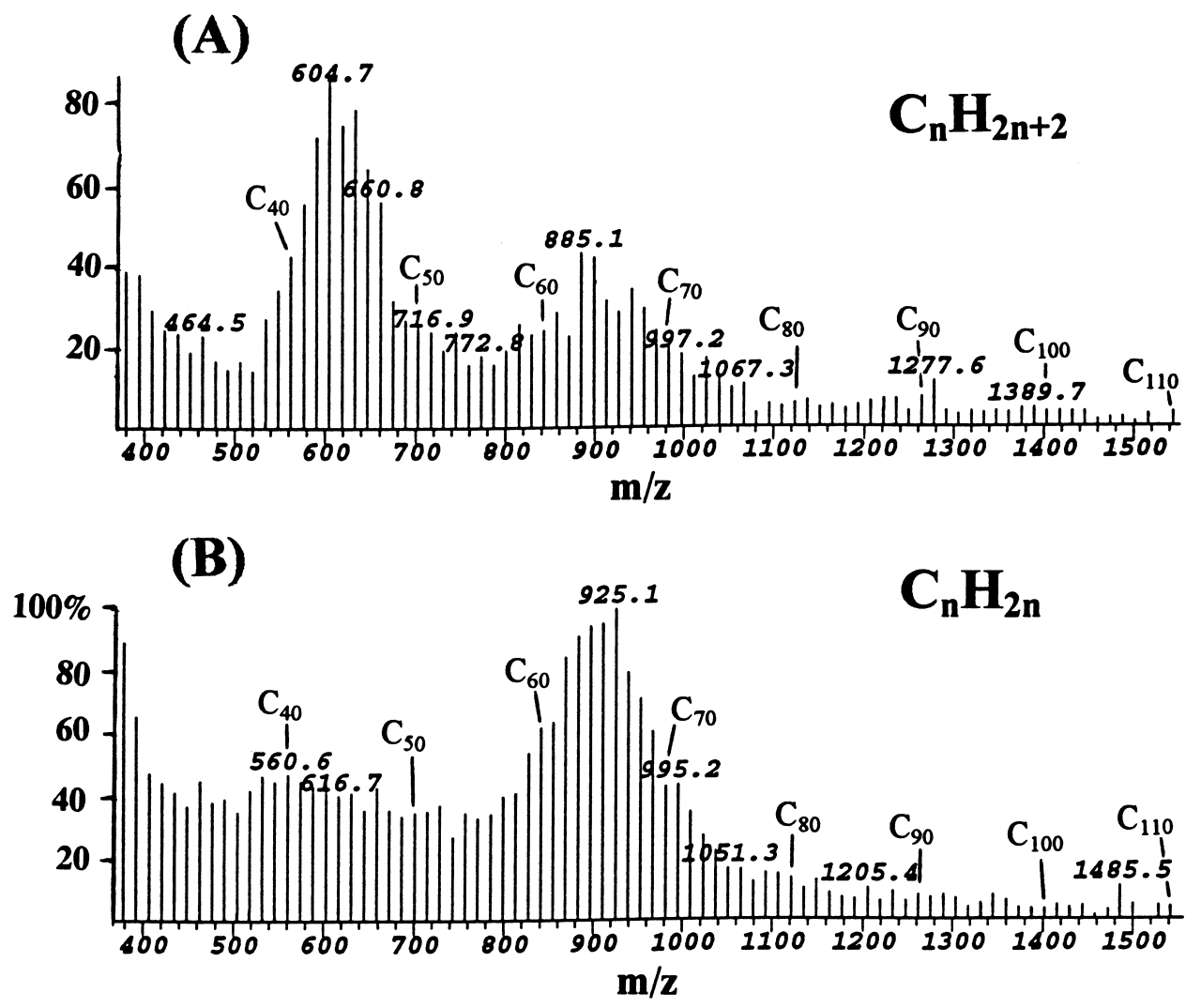

(C)

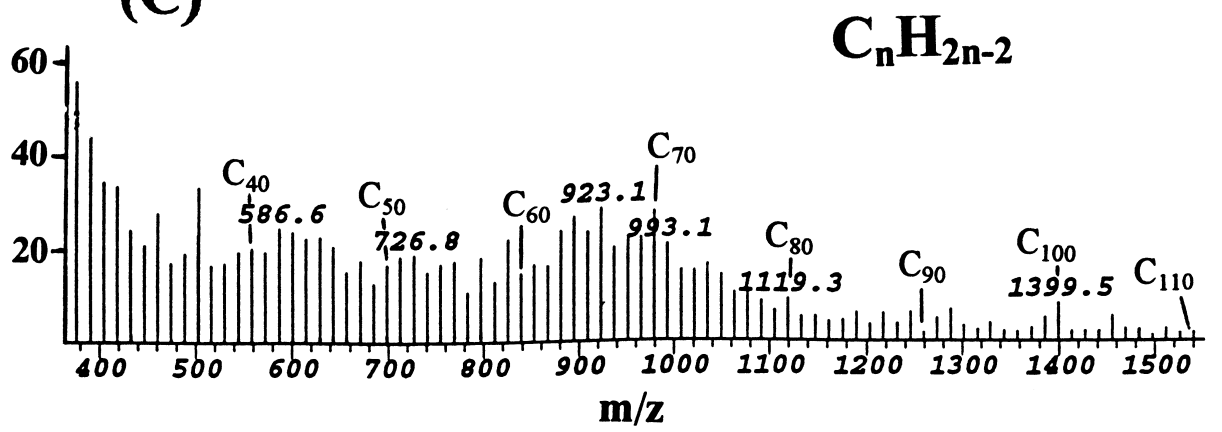

Fig. 3. FIMS of the series of molecular ions of compounds with different $Z$-number in the total saturate fraction of the ozocerite, with indication of their relative abundance. (A) $Z=2\left(\mathrm{C}_{n} \mathrm{H}_{2 n+2}\right)$; (B) $Z=0\left(\mathrm{C}_{n} \mathrm{H}_{2 n}\right)$; (C) $Z=-2\left(\mathrm{C}_{n} \mathrm{H}_{2 n-2}\right)$.

From the FI mass spectrum it is possible to calculate the number of carbon and hydrogen atoms present in the molecular ions and, hence, to display the distribution of hydrocarbons as a function of carbon number and $Z$-number (related to the degree of unsaturation; $\mathrm{C}_{n} \mathrm{H}_{2 n+Z}$ ). Fig. 3 shows the series of molecular ions in the FI mass spectrum with different $Z$-numbers. Intensities of the peaks have been converted to weight percent concentration by using relative ionization intensities, although no attempt was made to calculate response factors for each series of compounds. Series of compounds with none, one or two rings, corresponding, respectively, to the formula $\mathrm{C}_{n} \mathrm{H}_{2 n+2}, \mathrm{C}_{n} \mathrm{H}_{2 n}$ and $\mathrm{C}_{n} \mathrm{H}_{2 n-2}$, were observed in the ozocerite solid bitumen ranging up to near $\mathrm{C}_{110}$. Boduszynski $(1987,1988)$ have also reported the presence of multiple saturate and aromatic $Z$ series in the high molecular weight range, extending up to 2000 amu, in fractions of heavy petroleums. Relatively high amounts of an unusual series of tetracyclic hydrocar- 

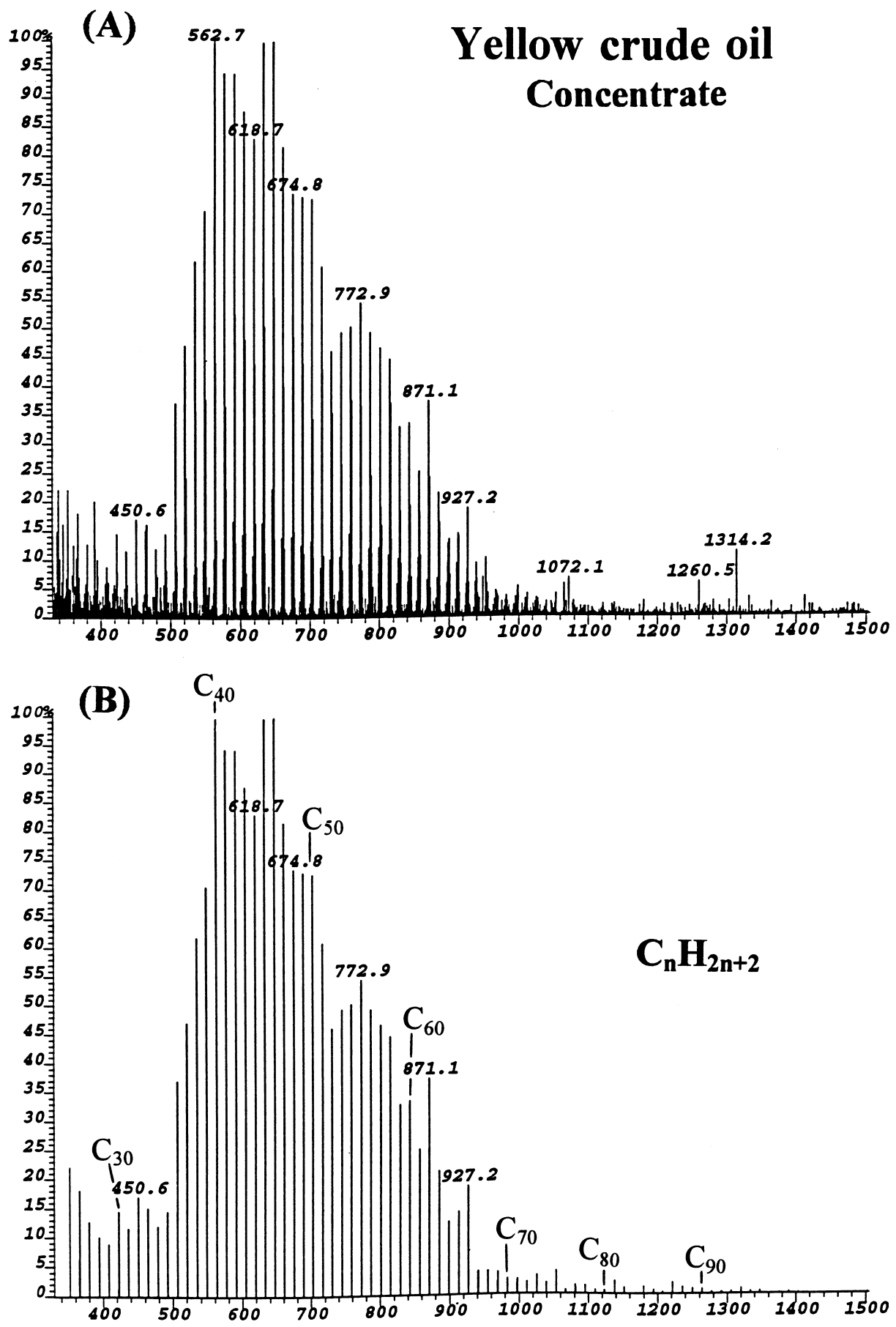

Fig. 4. FIMS analysis of the fraction enriched in high molecular weight hydrocarbons from the Yellow crude oil from the Bluebell Field by the addition of tetrahydrofuran, with indication of their relative abundance. (A) Complete FIMS profile; (B) plot of $\mathrm{C}_{n} \mathrm{H}_{2 n+2}$ ions $(\mathrm{Z}=2)$ corresponding to the acyclic components.

bons ranging up to $\mathrm{C}_{86}$ was identified in high-boiling cuts of the immature and biodegraded Kern River petroleum Boduszynski (1988). In the ozocerite solid bitu- men, however, series with more than two degrees of unsaturation could not be detected.

In the ozocerite solid bitumen, the series of alkanes 
(normal and branched) consisted in several overlapping bell-shaped distributions with maxima at $\mathrm{C}_{43}$ and $\mathrm{C}_{63}$. A similar distribution of $n$-alkanes with maxima centered at $\mathrm{C}_{42}$ and $\mathrm{C}_{61}$ in the high molecular weight region has also been observed in the wax from an Alberta Basin Paleozoic petroleum (Carlson et al., 1997). Normal and branched alkanes are not resolved in the FIMS. However, a detailed study of the high molecular weight hydrocarbons of the ozocerite solid bitumen by HTGC showed that the alkanes above $\mathrm{C}_{40}$ corresponded mainly to branched alkanes (del Río et al., 1992; Carlson et al., 1997). The series of monocyclic alkanes $\left(\mathrm{C}_{n} \mathrm{H}_{2 n}\right)$, on the other hand, presented maxima at $\mathrm{C}_{40}$ and $\mathrm{C}_{66}$ and are the predominant compounds occurring in the high molecular weight region (above $\mathrm{C}_{40}$ ). Parallel FIMS analyses of the ozocerite sample by Carlson (unpublished results) also displayed molecular ions corresponding to compounds with one double bond equivalent (monocyclic/alkene) as major components in the ozocerite, thus supporting the validity of our analyses. Finally, minor amounts of bicyclic hydrocarbons $\left(\mathrm{C}_{n} \mathrm{H}_{2 n-2}\right)$ could also be identified with maximum at $\mathrm{C}_{66}$ and ranging up to $\mathrm{C}_{110}$. The identification of hydrocarbons having branched and cyclic structures ranging up to $\mathrm{C}_{110}$ is of significant importance since they have the potential to be used as biomarkers and possibly supplement information already obtained from the more commonly used steranes and terpanes.

A previous study of the total saturate fraction of the ozocerite solid bitumen by DIP-EIMS showed the presence of molecular ions of hydrocarbons ranging up to $\mathrm{C}_{80}$ with a predominance of cycloalkyl moieties and branched alkanes in the high molecular weight region (del Río et al., 1992). Carlson et al. (1994, 1997) also confirmed that the HTGC retention times of the high molecular weight alkanes occurring in the ozocerite solid bitumen are different from those of the corresponding $n$-alkanes and that they are likely to be isoand/or monocyclic alkanes. Other authors have also reported that for carbon numbers over $\mathrm{C}_{40}$, iso- and/or monocyclic alkanes, rather than $n$-alkanes, dominate the HTGC profiles of many crude oils (Gallegos et al., 1991; Carlson et al., 1993).

The origin of these compounds is not yet completely understood. Maturation experiments of fatty acids in the presence of bentonite have produced high molecular weight alkyl cyclohexanes and mid-chain branched alkanes, similar to those identified in the ozocerite solid bitumen (del Río and Philp, 1992b). Catagenically-induced fragmentation reactions of hydrocarbon polymers have also been proposed as possible source of HMWHC (Tegelaar et al., 1989). On the other hand, the analysis of the ozocerite solid bitumen by HTGC-IRMS revealed that the mean isotopic composition of the individual $\mathrm{C}_{20}-\mathrm{C}_{40} n$-alkanes $\left(\delta^{13} \mathrm{C}=-\right.$ $31.7 \%$ ) corresponds to that of the $\mathrm{C}_{57}-\mathrm{C}_{65}$ high molecular weight alkanes (Carlson et al., 1997). The similarity in carbon isotope signatures of the high molecular weight hydrocarbons and lower molecular weight $n$-alkanes suggests that both groups of hydrocarbons are formed either biologically or diagenetically from the same ancient carbon pool.

Finally, another example of the use of FIMS for the analysis of high molecular weight hydrocarbons in a crude oil is shown in Fig. 4. A concentrate of HMWHC was isolated from the waxy yellow crude of the Bluebell Field by the addition of tetrahydrofuran to the saturate fraction. The FIMS spectrum of this concentrate shows a series of high molecular weight

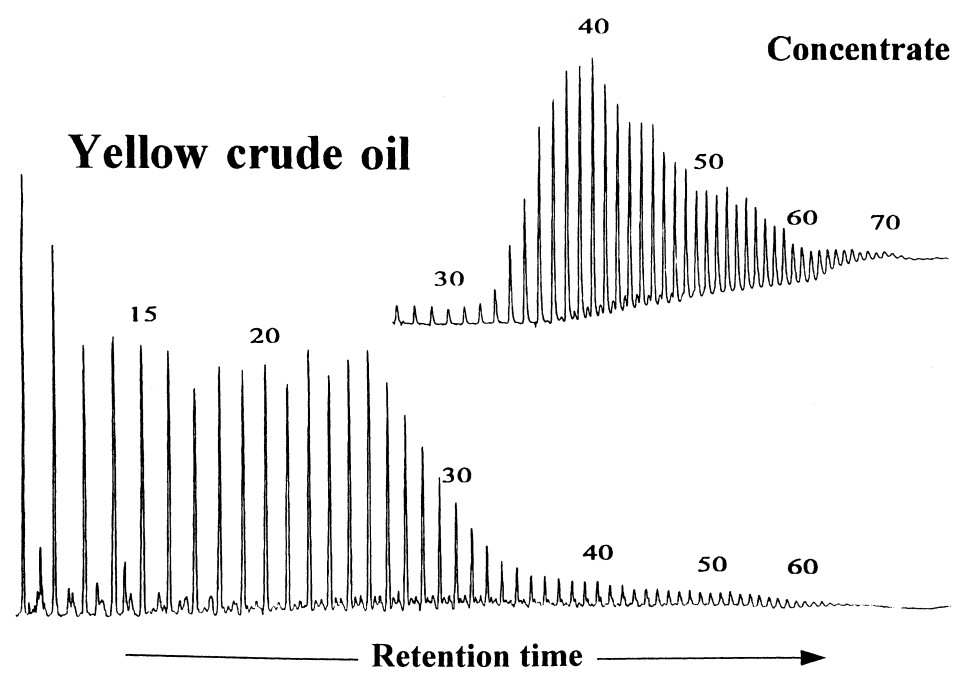

Fig. 5. Capillary HTGC (6 m) analysis of the Yellow crude oil from the Bluebell Field and its HMWHC concentrate (inset). 
alkanes $\left(\mathrm{C}_{n} \mathrm{H}_{2 n+2}\right)$ ranging up to near $\mathrm{C}_{100}$. Hydrocarbons with cyclic structures were not found in the high molecular weight region of this crude oil. In this case, a close examination of the HTGC trace (shown in Fig. 5) revealed that the alkanes present in the high molecular weight region correspond mainly to normal alkanes, in contrast to the ozocerite solid bitumen that showed a predominance of isoalkanes. The $n$ alkane series did not show a clear even/odd predominance. Although the yellow crude oil and the ozocerite belong to the Uinta basin and have high molecular weight hydrocarbons, the FIMS profiles are completely different, suggesting a different origin.

\section{Conclusions}

Field ionization mass spectrometry (FIMS) has allowed an extension of the range of hydrocarbons analyzed in geological materials. High molecular weight hydrocarbons ranging up to $C_{110}$ have been identified in an ozocerite solid bitumen and a waxy crude oil from the Uinta Basin (Utah). Series of branched, mono- and bicyclic alkanes up to $\mathrm{C}_{110}$ have been identified in the ozocerite, with a predominance of monocyclic alkanes in the molecular weight region (above $\mathrm{C}_{40}$ ). In contrast, only $n$-alkanes up to near $\mathrm{C}_{100}$ occurred in the waxy crude oil.

These data are significant as they greatly exceed the carbon numbers reported for biomarkers and the carbon numbers that are amenable to GC-MS $\left(<\mathrm{C}_{40}\right)$. From the FI spectra it is possible to calculate the number of carbon and hydrogen atoms present in each molecular ion, and hence to display the distribution of hydrocarbons as a function of carbon number and $Z$ number (which represents the degree of unsaturation or ring number). This technique is therefore ideally suited for the characterization of high molecular weight hydrocarbons in crude oils and solid bitumens since the molecular weight distribution can be directly determined and the contribution from all the components evaluated. The continuing study of high molecular weight hydrocarbons will provide additional information into the origin and types of organic source materials responsible for various types of oils, as well as fossil resins and bitumens. Major advances can be expected in the next few years because of the improvements in analytical techniques that will make it easier to identify high molecular weight hydrocarbons at the detailed molecular-structure level.

\section{Acknowledgements}

We thank VG Analytical (Manchester, UK) for kindly performing the FIMS analyses. The authors also thank Dr. R.M. Carlson for the valuable comments and suggestions for improvement of the manuscript.

\section{Associate Editor-A.G. Douglas}

\section{References}

Aquino Neto, F.R., Cardoso, J.N., Pereira, A.S., Fernandes, M.C.Z., Caetano, C.A., Machado, A.L.C., 1994. Application of high temperature high resolution gas chromatography to paraffinic deposits in petroleum production pipelines. Journal of High Resolution Chromatography 17, 259-263.

Boduszynski, M.M., 1987. Composition of heavy petroleums. 1. Molecular weight, hydrogen deficiency, and heteroatom concentration as a function of atmospheric equivalent boiling point up to $1400^{\circ} \mathrm{F}\left(760^{\circ} \mathrm{C}\right)$. Energy and Fuels 1, 2-11.

Boduszynski, M.M., 1988. Composition of heavy petroleums. 2. Molecular characterization. Energy and Fuels 2, 597613.

Carlson, R.M.K., Teerman, S.C., Moldowan, J.M., Jacobson, S.R., Chan, E.I., Dorrough, K.S., Seetoo, W.C., Mertani, B., 1993. High temperature gas chromatography of high wax oils. In: Proceedings of the 20th Annual Convention of the Indonesian Petroleum Association. Indonesian Petroleum Association, Jakarta, pp. 483-507.

Carlson, R.M.K., Jacobson, S.R., Boduszynski, M.M., Rechsteiner, C.A., Grudoski, D.A., 1994. Applications of high temperature gas chromatography to hard-to-recoveroils and natural bitumens. In: Alemasov, V.A., Muslimov, R.K., Romanov, G.V. (Eds.), Problems of Complex Development and Production of Hard-Accesible Oils and Natural Bitumens (Production and Refining), (Eds. Institute of Organic and Physical Chemistry, Kazan Scientific Centre, Russian Academy of Sciences, Kazan, pp. 1102-1133.

Carlson, R.M.K., Dias, R.F., Schoell, M., 1997. Origins of high molecular weight alkanes $>\mathrm{C}_{40}$ in waxes from natural crude oils and bitumens based on carbon isotopic evidence. In: Abstracts 18th Int. Meeting on Organic Geochemistry, Maastricht, The Netherlands, pp. 399-400.

de Grande, S.M.B., Aquino Neto, F.R., Mello, M.R., 1993. Extended tricyclic terpanes in sediments and petroleums. Organic Geochemistry 20, 1039-1047.

Gallegos, E.J., Fetzer, J.C., Carlson, R.M., Peña, M.N., 1991. High-temperature GC/MS characterization of porphyrins and high molecular weight saturated hydrocarbons. Energy and Fuels 5, 376-381.

Mueller, E., Philp, R.P., 1998. Extraction of high molecular weight hydrocarbons from source rocks: an example from the Green River Formation, Uinta Basin, Utah. Organic Geochemistry 28, 625-631.

Philp, R.P., 1994. High temperature gas chromatography for the analysis of fossil fuels: a review. Journal of High Resolution Chromatography 17, 398-406.

Philp, R.P., Bishop, A.N., del Río, J.C., Allen, J., 1995. Characterization of high molecular weight hydrocarbons 
$\left(>\mathrm{C}_{40}\right)$ in oils and reservoir rocks. In: Cubitt, J.M., England, W.A. (Eds.), The Geochemistry of Reservoirs, , pp. 71-85 Geological Society Special Publication No. 86.

del Río, J.C., Philp, R.P., 1992a. High molecular weight hydrocarbons: a new frontier in organic geochemistry. Trends in Analytical Chemistry 11, 187-193.

del Río, J.C., Philp, R.P., 1992b. Oligomerization of fatty acids as a possible source for high molecular weight hydro- carbons and sulphur-containing compounds in sediments. Organic Geochemistry 18, 869-880.

del Río, J.C., Philp, R.P., Allen, J., 1992. Nature and geochemistry of high molecular weight hydrocarbons (above $\mathrm{C}_{40}$ ) in oils and solid bitumens. Organic Geochemistry 18, 541-553.

Tegelaar, E.W., Matthezing, R.M., Horsfield, J.B.H., de Leeuw, J.W., 1989. Possible origins of $n$-alkanes in highwax crude oils. Nature 342, 529-531. 